\title{
A Study of Postural Loading in Malaysian Mining Industry using Rapid Entire Body Assessment
}

\author{
Norhidayah M.S. ${ }^{1, a}$, Nik Mohd Zuki Nik Mohamed ${ }^{1,}$ Muhamad Arifpin Mansor ${ }^{2}$ and Ahmad Rasdan Ismail ${ }^{3}$ \\ ${ }^{1}$ Faculty of Mechanical Engineering, Universiti Malaysia Pahang, 26600 Pekan, Pahang, Malaysia \\ 2 Faculty of Engineering Technology, Universiti Malaysia Pahang, Lebuhraya Tun Razak, 26300 Gambang, Pahang, Malaysia \\ ${ }^{3}$ Faculty of Creative Technology and Heritage, Universiti Malaysia Kelantan, Locked Bag 01. 16300 Bachok, Kelantan, Malaysia
}

\begin{abstract}
The ergonomics and environment factors have been the core issue for the mining industry for many years, and its profiles are rising. To ensure an ergonomics work environment, it is possible to require specific attention especially in this industries sector. It is becoming increasingly difficult to ignore the essential issue in Malaysia due to lack of ergonomics knowledge and low awareness among the engineers in the mining sector. The focus of this study is to evaluate and validate the physical risk factor associated with work-related musculoskeletal disorder (WMSDs) by using Rapid Entire Body Assessment (REBA) among mining industry workers. All the physical risk factors involved the main body regions such as upper arm, lower arm, wrist, trunk, neck and leg that has been identified associated with WMSDs. There were 18 subjects were selected to involve in this study. Those subjects were chosen according to their job task. To increase the reliability of the result, each subject was evaluated thrice in the trials. From the analysis, the average of final score of the REBA is 8.24 indicates high risk and calls for engineering/or work method changes to reduce or eliminate muscular disorder risk. The results of the analysis were used to improve the process of work, design of workstation and also improving the work posture to enhance the comfort level of operators. This study is crucial among the mining industry that is a lack of the information and research about the ergonomics issues in the industry. The overall finding indicated that the whole process of selected work task will contribute to musculoskeletal disorder either for a short or long time exposure.
\end{abstract}

\section{Introduction}

In recent years, there has been an increasing interest in quality, health and safety requirement in several occupations. Researchers have increased interest in occupational safety and health issue for mining industries in Malaysia. It is becoming gradually more difficult to ignore the issue related to occupational workplace ergonomics risk assessment due the recent studies and statistics. According to statistic report by the Department of Occupational Safety and Health, Malaysia (DOSH) 3 of victims were reported for the category of Death until June 2014, 17 of victims were reported for NonPermanent Disability (NPD) and 3 of victims were reported for Permanent Disability for mining industries [1]. Furthermore, according to statistics report on the number of accidents by industry for the past year 2012 conducted by Social Security Organisation, (SOCSO), 9 cases were reported for fatal accident and 417 cases were reported for disability in mine and quarry industry [2].

However, those accidents can be minimized throughout the application of engineering and administrative controls [3]. Lack of information about ergonomics is observed in the various industries in which task are carried out. Musculoskeletal disorders are

\footnotetext{
${ }^{\mathrm{a}}$ Corresponding author: hidayahsout@gmail.com
}

observed in the welding process where workers are working in kneeling posture, and it shows that there is need to adjust the body postures [4]. The purpose of ergonomic principles would help to enhance machine performance and productivity, help workers to be comfortable and safe [5]. Some workers work under harsh conditions to carry out the required task. These tough circumstances normally increase to various MSD within the workers. These disorders emerge within the workers body due to repetitive lifting, differential lifting height, ambient conditions, etc. [6]. The significance of ergonomics should be product design, working environment, and industrial workstation design, in order to increase productivity and reduce MSD among the workers.

The study exposed that there had been numerous gaps in the work environment, tools, and equipment that affect the health and safety of workers at the work site [8]. Ergonomics related to the design of methods and processes can help reduce or decrease works related risks, as well as advance the company's quality and productivity [9]. Awkward posture, lifting, forceful movement and physical work at rapid rate contribute to the musculoskeletal disorder. The Current study is focused on assessing the work posture of worker 
occupied in different activities of casting [10]. The application of ergonomic principles not only help to increase machine performance and efficiency, but also help the human operator to be comfortable and protected [11]. It was found that: there was the lack of ergonomics development and methods in small scale forging industry. A significant proportion of the workers were working in very terrible postures. It is recommended that the implementation of ergonomics intervention with accurate awareness among worker [12]. The Study recommended that an ergonomic workstation design can contribute widely to improve the physiological performance of the operators [13].

Therefore, MSD is a regular disorder characterized by ergonomics. Whereby, 448 cases were reported by, SOCSO [2]. The increasing cases reported can be the major issues for the workers are at high risk of developing WMSDs that are associated with exposure factors in this work environment. Despite the high prevalence of work-related musculoskeletal disorder (WMSDs) in mining industries, therefore the aims of this study is to investigate the physical risk factor among the workers in selected job task by using Rapid Entire Assessment (REBA) introduced by Hignett \& McAtamney[14]. The aim for this study is to evaluate and validate the physical risk factor associated with workrelated musculoskeletal disorder (WMSDs) by using Rapid Entire Body Assessment (REBA) among mining industry workers.

\section{Methodology}

\subsection{Subjects and selected job task}

Selected mining companies in Pahang and Kelantan states were randomly selected as a field study in this research. From the three workplace of the mining industry, 18 workers in the selected job were randomly selected as subjects. The selected job task was wet screening that related to screening the raw material by using manual handling hose.

The work task was based on the main procedure of selecting the best raw material before the next process continues. Those workers handle the hose manually to screening all the raw material from 8.00 am in the morning until $5.00 \mathrm{pm}$ afternoon with 30 to 45 minutes break at $1.00 \mathrm{pm}$. The hose weight more than $20 \mathrm{~kg}$ under strong pressure, and their body was excessively exposed to repetitive motion throughout the working hours. All subjects were exposed to standing position while handling the hose manually. The investigation was taken three times, in the morning, at noon and after the noon session.

\subsection{REBA method}

The concepts of assessing risk in REBA methods can be used to develop solutions leading to a comprehensive method appropriate for all work tasks and all parts of the body [15]. Basically the idea of REBA has been developed to fill a perceived need for a practitioner's field tool, specifically designed to be sensitive to the type of unpredictable working posture found in health care and other service industries [16]. There were several researches that used REBA methods as their ergonomics tools in several industries. The user of the tools needs to observe the worst posture and time aspect not considered. Janowitz et al. (2006) had measured the physical demands of work in hospital setting by using REBA and the result showed that the inter-rater reliability kappa was 0.54 for UB and 0.66 for LB. The scoring algorithm demonstrated significant variation $($ ANOVA $p<0.05)$ by occupation in anticipated directions (administrators ranked lowest; support staff ranked highest on both scores). A supplemental self-assessment measure of spinal loading correlated with high strain LB scores $(\mathrm{r}=$ $0.30 ; \mathrm{p}<0.001)[17]$.

All risk assessment methodologies examined by using REBA with agreed a level of risk was associated with performance of the saw-filer job and compare the results of 5 ergonomic risk assessment methods calculated with quantified physical exposure information [18]. REBA is sensitive to musculoskeletal risk in variety of task such as the assessment of working postures in health care and service industries. It concentrates on upper arm, lower arms, wrists, trunk, neck and legs[16] which is suitable method for postural loading tools in mining industry. In a user study ( $\mathrm{N}=18$ participants) a group with the REBA feedback was compared to a control group. The levels of MSD demonstrate that the real-time ergonomics feedback significantly decreased the risk of MSDs at global and segmental levels. The real-time ergonomics tool presented in this study could be used directly to reduce the risk of MSDs in an industry and to optimize the long-term performance of workers. The results of REBA score involve the neck, legs, trunk, arm lower, wrist, upper arm, force and coupling to get the final score to determine the level of MSD for the selected job task. The main value to be considered were the mean, maximum, minimum and standard deviation (SD) to validate and evaluate the significant of WMSDs and the physical risk factor involve.

\section{Results and discussion}

\subsection{Description of the subjects}

From the wet screening job, out of 18 workers, the age range from 19 to 36 years (mean $2.44 \pm 0.86$ ). The working experience ranges was from less than a year to 5 years (mean $1.89 \pm 0.47$ ). Table 1 shows the demographics of the workers in wet screening.

Table 1. Demographics of the workers in wet screening job

\begin{tabular}{|c|c|c|c|c|c|c|}
\hline \multirow{2}{*}{ Job } & \multicolumn{3}{|c|}{ Age (year) } & \multicolumn{3}{c|}{ Working experience } \\
& Mean & SD & Range & Mean & SD & Range \\
\hline $\begin{array}{c}\text { Wet } \\
\text { Screening }\end{array}$ & 2.44 & 0.86 & $19-36$ & 1.89 & 0.47 & $<1-5$ \\
\hline
\end{tabular}

\subsection{Results and analysis}


The Figure 1 shows the REBA assessment during the morning session. The neck score was $1.06 \pm 0.24$ as the highest score was 2 as the neck position located at the range of $20^{\circ}+$ from the natural position of the neck. Legs score was $2.17 \pm 0.38$ as the highest score was 3 as the operators can freely move throughout the REBA assessment with the adjustable leg between $30^{\circ}$ to $60^{\circ}$. Trunk score was $2.11 \pm 0.32$ and had the same highest score with legs score was 3. Most of the operators were repetition movement with the range of the trunk between $0^{\circ}$ to $20^{\circ}$. The operators' lower arm positions were always at the range of $0^{\circ}$ until to $100^{\circ}$ from the natural of the lower arm position, hence the score was $1.78 \pm 0.43$. The wrist mean score was $1.0 \pm 0.0$ as all of the operators had locate wrist position as same with each other because they had most the same of wrist position throughout the REBA assessment. Upper arm score was $3.0 \pm 0.0$ as all the operators had the same position at the range $20^{\circ}$ to $45^{\circ}$ in handling the equipment throughout the REBA assessment. The score for force was $2.0 \pm 0.0$ as the loading was more than $10 \mathrm{~kg}$ for each operator. Coupling score was $1.0 \pm 0.0$ as the acceptable coupling with another body part of the operators along the working job performance. Final mean score was $8.11 \pm 1.78$ and it is indicates high risk and calls for further investigation and engineering or method changes to reduce or eliminate musculoskeletal risk for the selected work task.

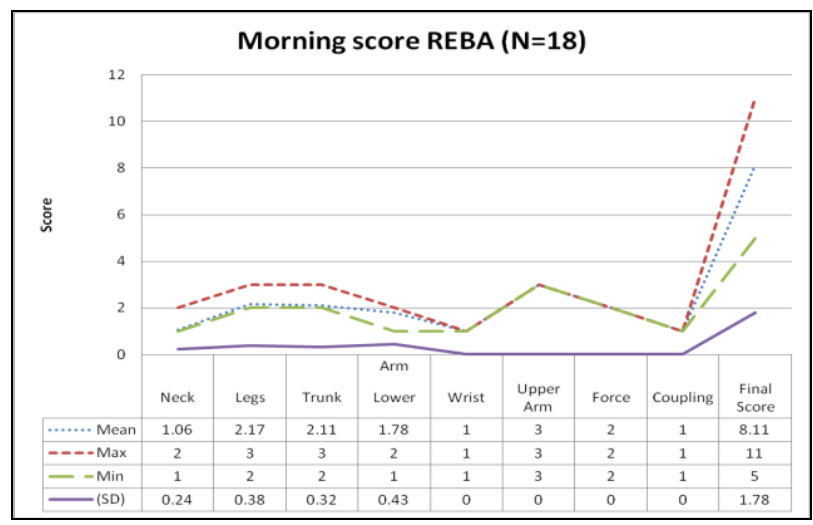

Figure 1. REBA Morning Score

The next Figure 2 was explained the REBA assessment for noon session. From the data, neck score was $1.06 \pm 0.24$ as the most of the operators were locate natural neck position between the ranges of $0^{\circ}$ to $20^{\circ}$. Legs score was $2.17 \pm 0.38$ which was most of the operators can move the legs and adjust to the range of $30^{\circ}$ to $60^{\circ}$ during the working job task. Trunk score was $2.11 \pm 0.32$ as the highest score was 3 . There was some of the operators had trunk position at the range $20^{\circ}$ to $60^{\circ}$ from the natural position as the position of their workstation cause the operators need to bent forward during the working job task. The score for lower arm was $1.78 \pm 0.43$ which was caused of the range of work task was around $0^{\circ}$ until $100^{\circ}$ during handling the equipment at the workstation. As the score for lower arm was $1.0 \pm 0.0$ obtain the wrist score also had no changes with REBA assessment compare to morning session. Upper arm score was remain same as morning session at $3.0 \pm 0.0$ because the upper arm position does not have major changes between the morning and noon session throughout the working REBA assessment. The force score still had the same score as previous REBA assessment at $2.0 \pm 0.0$ with the same loading with more than $10 \mathrm{~kg}$ involved in the working job task. Coupling score also remain same as before with score at $1.0 \pm 0.0$ as all the operators had the same coupling handling in the working task. For the final score was $7.94 \pm 1.86$ which is indicates medium risk with further investigation and need to be change the type of working station soon.

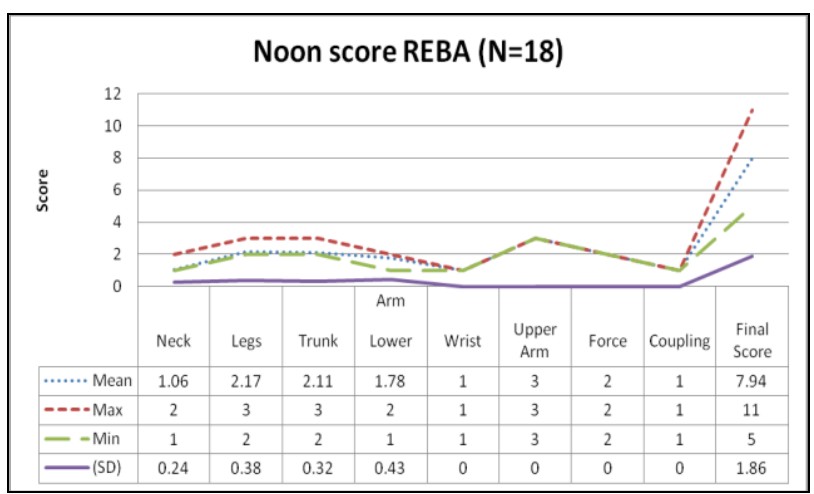

Figure 2. REBA Noon Score

Figure 3 below shows the slight different score between the physical risk factor of REBA assessment after the noon session. As the neck score had slight lower score than noon session at $1.0 \pm 0.0$. Legs score showed slightly higher than noon session at $2.22 \pm 2.3$, because of there were few operators that had the same posture for the whole day working task. The trunk score was $2.22 \pm 0.0$ had slightly increase score compare to noon session assessment. Lower arm score was $2.0 \pm 0.0$ which means all the operators had the same position of lower arm for the rest of REBA assessment after the noon session. The wrist score does not had any different changes for the whole day at $1.0 \pm 0.0$. Same goes with upper arm score with same score as morning and noon session at 3.0 \pm 0.0 because the operators were had same position during the REBA assessment from morning till after noon. The work task had same loading force which was more than $10 \mathrm{~kg}$ involved. The coupling score was $1.0 \pm 0.0$ same as other session and acceptable with another body part toward the coupling work task. Final score was $8.67 \pm 1.14$ indicates the high risk and calls for further investigation and engineering with method changes to reduce or eliminate musculoskeletal disorder risk.

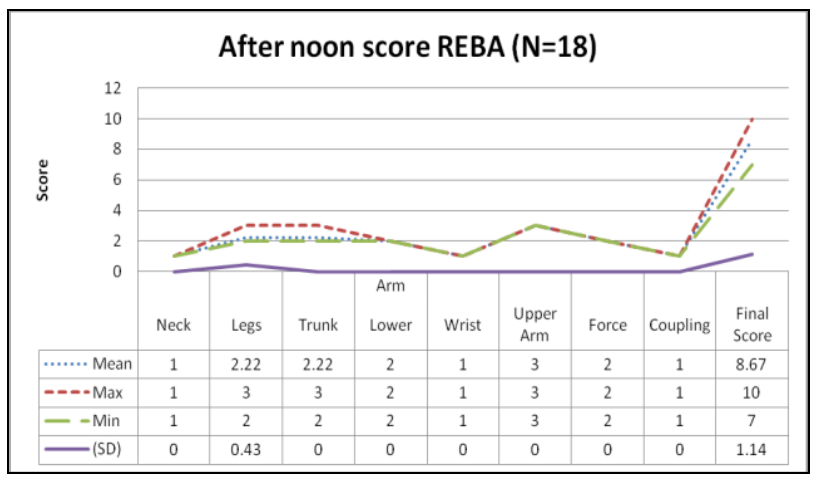

Figure 3. REBA After noon Score 


\section{Conclusions}

The result of this assessment shows that the subjects were exposed to all the physical risk factors such as neck, trunk, and upper extremities. As a conclusion, we can say that the wet screening task was in very high-risk level and need to be change immediately. The task needs to be revamped change for the health concern to the workers involve. The present study was designed to determine the level of physical MSD risk among the workers in mining. The further study needs to be done to ensure the cause of significant risk factors to the WMSDs among the mining workers.

\section{References}

1. DOSH, Statistic Report of Occupational accidents for the category of death until August 2010.Department of Occupational Safety and Health, Malaysia, 2010a.

2. SOCSO, Statistic report about the numbers of accidents by industry year 2007 Social Security Organization, Malaysia, 2007.

3. Isa Halim \& Abdul Rahman Omar, "A Review on Health Effects Associated with Prolonged Standing in The Industrial Workplaces," International Journal Of Research And Review In Applied Science, vol. 8, issue 1, July 2011.

4. D. N. Agrawal et al.," Study and Validation of Body Postures Of Workers Working In Small Scale Industry through Rula," International Journal of Engineering Science and Technology, Vol. 3 No.10 October 2011

5. Aide Maldonado-Macias et al., "Ergonomic Evaluation of Work Stations Related With the Operation of Advanced Manufacturing Technology Equipment: Two Cases of Study", XV CONGRESO INTERNACIONAL DE ERGONOMIA SEMAC, 2009.

6. Aman Sachdeva et al., "Minimizing Musculoskeletal Disorders in Lathe Machine Workers," International Journal of Ergonomics, Volume 1 Issue 22011.

7. Mohammad Iqbal et al., "Ergonomics and Design," International Conference on Industrial Engineering and Operations Management Kuala Lumpur, Malaysia, January $22-24,2011$.

8. Parimalam P. et al., "Ergonomic interventions to improve work environment in garment manufacturing units," Indian Journal of Occupational and Environmental Medicine, August 2006 -Volume 10 - Issue 2.

9. M. C.I. Javier Antonio Lom Holguín et al., "Ergonomics and its relationship to the design of production processes," Ponencia Conergo 2008.

10. Lakhwinder Pal singh., "An Investigation Work Posture Of Workers Engaged In Casting Industry: A Study In India,"Asian Journal of Managerial Science, Volume 1 Number 1, January - June 2012.

11. Asim Zaheer et al., "Ergonomics: A work place realities in Pakistan," International Posture Journal of
Science \& Technology, Volume 2, Issue 1, April, 2012.

12. L. P. Singh., "Work Posture Assessment in Forging Industry: An Exploratory Study in INDIA," International Journal of Advanced Engineering Technology, vol. 1 issue III Oct.-Dec. 2010.

13. Isa Halim et al., "Posture, muscle activity and oxygen consumption Evaluations among metal stamping operators: A pilot study in Malaysian small and medium Industries," Journal - The Institution of Engineers, Malaysia, Vol. 72, No. 4, December 2011.

14. S. Hignett and L. McAtamney, "Rapid entire body assessment (REBA)," Appl. Ergon., vol. 31, pp. 201205, 2000.

15. Roman-Liu, "Comparison of concepts in easy-to-use methods for MSD risk assessment.," Appl. Ergon., vol. 45, no. 3, pp. 420-7, May 2014.

16. J. Singh and K. Rula, "A Literature Review On MSDs Using Ergonomic Body Assessment Tools : RULA And REBA Himanshu Chaudhary," pp. 147 $149,2013$.

17. I. L. Janowitz, M. Gillen, G. Ryan, D. Rempel, L. Trupin, L. Swig, K. Mullen, R. Rugulies, and P. D. Blanc, "Measuring the physical demands of work in hospital settings: design and implementation of an ergonomics assessment.," Appl. Ergon., vol. 37, no. 5, pp. 641-58, Sep. 2006.

18. T. Â. Jones and S. Kumar, "Comparison of ergonomic risk assessments in a repetitive high-risk sawmill occupation: Saw-filer," vol. 37, pp. 744753, 2007. 